\title{
FATORES ETÁRIOS NO LEUCOGRAMA DE FÊMEAS ZEBUÍNAS SADIAS DA RAÇA NELORE (BOS INDICUS )
}

\author{
INFLUENCE OF AGE ON THE LEUKOGRAM VALUES \\ FOR HEALTHY NELORE (ZEBU) CATTLE
}

\section{Joselito Nunes Costa ${ }^{1}$ Fernando José Benesi ${ }^{2}$ Eduardo Harry Birgel $^{3}$ José Luiz D'Angelino $^{4}$ Maria Consuelo Caribé Ayres ${ }^{1}$ Ivan Roque de Barros Filho ${ }^{5}$}

\section{RESUMO}

Para avaliar-se a influência dos fatores etários sobre o leucograma de fêmeas zebuínas da raça Nelore, examinaram-se amostras de sangue de 158 animais, distribuídos por sete grupos etários (até 3 meses; 3 a 6 meses; 6 a 12 meses; 12 a 24 meses; 24 a 48 meses; 48 a 72 meses e maior que 72 meses). Os resultados expressos em valores médios ( \pm desvios padrões) máximo (máx.) e mínimo (mín.) em milhares de células por $\mathrm{mm}^{3}$ para os diferentes componentes do leucograma foram os seguintes: leucócitos total máx. - $16992 \pm 4104$ ( 6 a 12 meses) e min. $10353 \pm 2397$ (48 a 72 meses ) ; neutrófilos total máx. - $3931 \pm$ 1578 (até 3 meses) e min. - $2416 \pm 1118$ ( 6 a 12 meses ); eosinófilos máx. - $999 \pm 499$ (24 a 48 meses) e min. - $265 \pm 276$ ( 3 a 6 meses ); basófilos máx. - $67 \pm 88$ (> 72 meses) e min. - $39 \pm 78$ (6 a 12 meses); linfócitos típicos máx. - $12758 \pm 3608$ (6 a 12 meses) e min. - $5906 \pm 1883$ (48 a 72 meses); linfócitos atípicos máx. $1310 \pm 603$ (3 a 6 meses ) e min. - 760 4419 ( 48 a 72 meses ); linfócitos total máx. - $14079 \pm 4027$ (6 a 12 meses ) e min. - 6666 \pm 2059 ( 48 a 72 meses ); monócitos máx. $-27 \pm 62$ (até 3 meses ) e min.- O ( 6 a 12 meses). A existência de diferenças ( $p>0,05)$ entre grupos demonstrando diminuição dos neutrófilos e aumento dos linfócitos no primeiro ano de vida; a diminuição dos valores do total de leucócitos a partir de um ano de idade, como reflexo de comportamento similar dos números de linfócitos (típicos e atípicos) e o aumento dos eosinófilos entre 24 e 48 meses de vida, caracterizaram a influência dos fatores etários sobre a variação dos valores dos componentes do leucograma de fêmeas zebuínas da raça Nelore criadas em São Paulo - Brasil.

Palavras-chave: hematologia, leucograma, bovinos, nelore, idade.

\section{SUMMARY}

In order to evaluate the influence of the age on the white blood cell counts of Nelore (Zebu) cattle, 158 blood samples from seven groups of different ages (group I-up to three months; group II-three to six months; group III-six to 12 months; group IV-12 to 24 months; group V-24 to 48 months; group VI-48 to 72 months and group VII-older than 72 months) were studied. The highest and lowest mean values observed were total white blood cell/mm $\mathrm{mm}^{3}-16992 \pm 4104$ (group III) and 10353+2397 (group VI); neutrophils $/ \mathrm{mm}^{3}-3931 \pm 1578$ (group I) and $2416 \pm 1118$ (group III); eosinophils/ $\mathrm{mm}^{3}-999 \pm 499$ (group V) and $265 \pm 276$ (group II); basophils $/ \mathrm{mm}^{3}-67 \pm 88$ (group VII) and $39 \pm 78$ (group III); typical lymphocytes/ $\mathrm{mm}^{3}-12758 \pm 3608$ (group III) and $5906 \pm 1883$ (group VI); atypical lymphocytes/ $\mathrm{mm}^{3}-1310 \pm 603$ (group II) and $760 \pm 419$ (group VI) ; lymphocytes total/ $\mathrm{mm}^{3}$ $14079 \pm 4027$ (group III) and 6666 \pm 2059 (group VI); monocytes $/ \mathrm{mm}^{3}-27 \pm 62$ (group I) and 0 (group III). The differences $(p>0.05)$ observed among the groups in relation to total white blood cell, lymphocytes, neutrophils and eosinophils can be related to the influence of the age on leukogram of Nelore (Zebu) cattle raised in São Paulo-Brazil

Key words: hematology, leukogram, age, cattle, Nelore breed

\section{INTRODUÇÃO}

A influência dos fatores etários, sexuais e raciais sobre as variações do leucograma de bovinos mereceu o estudo de vários autores ( GREATOREX, 1954, 1957a, 1957b; TENNANT et al., 1974;

\footnotetext{
${ }^{1}$ Professores Assistentes da Escola de Medicina Veterinária da Universidade Federal da Bahia.

${ }^{2}$ Professor Associado, Departamento de Clínica Médica da Faculdade de Medicina Veterinária e Zootecnia da Universidade de São Paulo (USP), Av. Professor Doutor Orlando Marques de Paiva, 87, CUASO. São Paulo, SP, 05508-000. E-mail: borges@usp.br. Autor para correspondência.

${ }^{3}$ Professor Titular, Departamento de Clínica Médica da Faculdade de Medicina Veterinária e Zootecnia da USP.

${ }^{4}$ Professor Associado, Departamento de Clínica Médica da Faculdade de Medicina Veterinária e Zootecnia da USP.

${ }^{5}$ Professor Assistente da Faculdade de Medicina Veterinária da Universidade Federal do Paraná.
} 
LUMSDEN et al., 1980; GARCIA, 1989; BIRGEL JUNIOR, 1991). Assim, GREATOREX (1954) avaliou as modificações do quadro leucocitário em 233 bovinos das raças Ayrshire, Shorthorn, Guernsey, e Holandesa. O pesquisador observou que o percentual de neutrófilos decrescia conforme a idade aumentava, contrapondo-se uma elevação do percentual dos linfócitos, desde o nascimento até os animais completarem um ano de idade. Em 1956, HOLMAN analisou as modificações demonstradas no sangue de 2212 bezerras e novilhas da raça Ayrshire, destacando que os linfócitos ao nascimento representavam $33 \%$ da contagem leucocitária diferencial e, aos quatro meses, apresentavam valores tão elevados quanto $72 \%$, para posteriormente decrescerem levemente. TENNANT et al. (1974) consideraram o leucograma de 184 bezerros desde o nascimento até a terceira semana de idade, demonstrando que o número total de leucócitos era maior ao nascimento, decrescendo significativamente nos dois primeiros dias de vida, e que o número de neutrófilos diminuía continuamente durante os primeiros cinco dias após o nascimento. ROSAL et al. (1982) determinaram os valores do leucograma de 46 bovinos da raça Indubrasil, desde o nascimento até 40 semanas de vida, evidenciando a influência dos fatores etários, uma vez que os números de linfócitos e de eosinófilos aumentavam, conforme evoluía a idade. GARCIA (1989) examinou amostras sangüíneas de 797 bovinos da raça Holandesa, livres (374) ou infectados (423) pelo Vírus da Leucose BovinaVLB. A infecção determinada por esse vírus não interferiu sobre os valores absolutos dos neutrófilos, eosinófilos, basófilos e monócitos, porém, determinou, nos animais infectados, uma leucocitose por linfocitose. BIRGEL JUNIOR (1991) analisou o leucograma de 449 animais da raça Jersey, destacando que os fatores etários exerceram influência sobre o leucograma, caracterizada por aumento do número de leucócitos até 12 meses de idade, quando se estabilizava, para, a seguir, diminuir progressivamente com o desenvolvimento etário. Em 1992, ADAMS $\boldsymbol{e t}$ al. realizaram pesquisa com o objetivo de monitorar variáveis hematológicas em bezerros do período do nascimento até três semanas de idade, demonstrando que o número total de neutrófilos segmentados foi maior ao nascimento do que após dois dias de vida, e que o dos linfócitos dobrou até a terceira semana de vida. BIONDO (1996) investigou a influência dos fatores etários e sexuais sobre o leucograma de 127 bovinos da raça Nelore (71 machos e 56 fêmeas), durante os primeiros 30 dias de vida, concluindo que ocorreu um aumento dos linfócitos e diminuição dos neutrófilos com a evolução etária. Considerando-se a escassez de pesquisas nacionais sobre o leucograma de zebuínos e a importância deste conhecimento na prática da clínica buiatrica, objetivou-se, com este trabalho, o estabelecimento de valores de referência para o leucograma de bovinos sadios ( não reagentes ao antígeno do VLB) da raça Nelore, criados no Estado de São Paulo, avaliando-se a influência dos fatores etários sobre as suas variações.

\section{MATERIAL E MÉTODOS}

Para atingir-se os objetivos propostos neste estudo, analisaram-se amostras de sangue colhidas de 158 fêmeas, zebuínos da raça Nelore criados no Estado de São Paulo, clinicamente sadias e não reagentes ao antígeno do VLB. Os animais utilizados, pertencentes a propriedades localizadas nos municípios de Indaiatuba, Brotas, São Carlos, Analândia e Descalvado - Estado de São Paulo, foram distribuídos, por sete grupos experimentais, conforme as faixas etárias a seguir: 0 a 3 meses; 3 a 6 meses; 6 a 12 meses; 12 a 24 meses; 24 a 48 meses; 48 a 72 meses e maiores que 72 meses. Realizou-se a colheita de sangue, através de punctura da veia jugular externa, sem garroteamento excessivo do vaso, usando-se agulha 40x16. Cerca de $5 \mathrm{ml}$ de sangue foram depositados em frascos contendo 0,05 ml de solução aquosa de EDTA a $10 \%$ e destinados a hematimetria. As amostras foram mantidas refrigeradas até o momento da realização dos exames, sendo estes concluídos antes de decorridas 24 horas da colheita. Com o sangue in natura de cada animal, foram confeccionados dois esfregaços destinados à contagem diferencial dos leucócitos. As amostras de soro sangüíneo, utilizadas para a pesquisa da presença ou não de anticorpos anti-VLB, foram obtidas de alíquotas de sangue colhidas em tubos de ensaio de $100 \times 15 \mathrm{~mm}$, os quais, após a retração do coágulo, foram centrifugados e os soros separados por aspiração. Esses soros foram mantidos congelados a menos $20^{\circ} \mathrm{C}$ até o momento da realização da prova para o diagnóstico da Leucose Enzoótica Bovina. As contagens dos números total e diferencial dos leucócitos, bem como a prova de imunodifusão radial em gel de agar para determinação de anticorpos séricos anti-VLB, foram efetuadas de acordo com a padronização e recomendações estabelecidas por BIRGEL (1982).

A influência dos fatores etários sobre as variações dos componentes do leucograma de zebuínos da raça Nelore foi avaliada, aplicando-se inicialmente a análise de variância e a seguir o Teste de Bonferroni para comparação entre médias, tendo que ser o valor de p, em nível de 5\% de probabilidade, menor do que 0,002381 (BAILEY,1977). 


\section{RESULTADOS}

Os resultados obtidos no presente trabalho, sumarizados na tabela 1 , permitem afirmar que os fatores etários exerceram influência significativa sobre o número total de leucócitos de zebuínos da raça Nelore, criados no Estado de São Paulo, evidenciando-se pequenas variações do número médio total de leucócitos até 12 meses de idade, quando atingiu a magnitude máxima $\left(16992 \pm 4104 / \mathrm{mm}^{3}\right)$, para, a seguir, observar-se queda expressiva dos valores, registrando-se o número mínimo nos animais cujas idades variavam entre 48 e 72 meses $\left(10353 \pm 2797 / \mathrm{mm}^{3}\right)$. Nos animais com idade superior a 72 meses, constatou-se estabilização dos valores $\left(11835 \pm 1753 / \mathrm{mm}^{3}\right)$. A observação do valor máximo para o total de leucócitos refletiu particularmente a variação do número total de linfócitos típicos (pequenos e grandes), para os quais se observou um aumento do número absoluto durante o primeiro ano de vida. $\mathrm{O}$ valor médio máximo foi detectado nos animais com idade entre 6 e 12 meses $\left(12758 \pm 3608 / \mathrm{mm}^{3}\right)$. Após esse período, os linfócitos típicos demonstraram uma diminuição do número absoluto, verificando-se o valor mínimo, para o grupo de animais com idade entre 48 e 72 meses $\left(5906 \pm 1883 / \mathrm{mm}^{3}\right)$. Os linfócitos atípicos apresentaram número máximo $\left(1310 \pm 603 / \mathrm{mm}^{3}\right)$ entre 3 e 6 meses de vida, seguido por queda dos valores, a partir dos 48 meses de idade. O número de neutrófilos com núcleo segmentado também sofreu influência dos fatores etários, tendo o maior valor médio no grupo de bezerros com até três meses de vida $\left(3918 \pm 1578 / \mathrm{mm}^{3}\right)$, apresentando na seqüência um declínio, sendo o número mínimo observado nos animais com 6 a 12 meses de idade $\left(2416 \pm 1118 / \mathrm{mm}^{3}\right)$. Os fatores etários também exerceram influência sobre o número absoluto de eosinófilos, pois evidenciou-se um aumento do número dessas células, no grupo de animais com idades variando entre 24 e 48 meses, para após estabilizarse nos grupos experimentais constituídos por animais mais velhos. Os números absolutos de neutrófilos com núcleo em bastão, de basófilos e de monó-

Tabela 1 - Leucograma de fêmeas zebuínas sadias da raça Nelore, criadas no Estado de São Paulo, segundo os grupos etários. Números absolutos (células $/ \mathrm{mm}^{3}$ ) expressos em valores médios com desvios padrões e resultados da avaliação estatística obtidos na comparação entre médias.

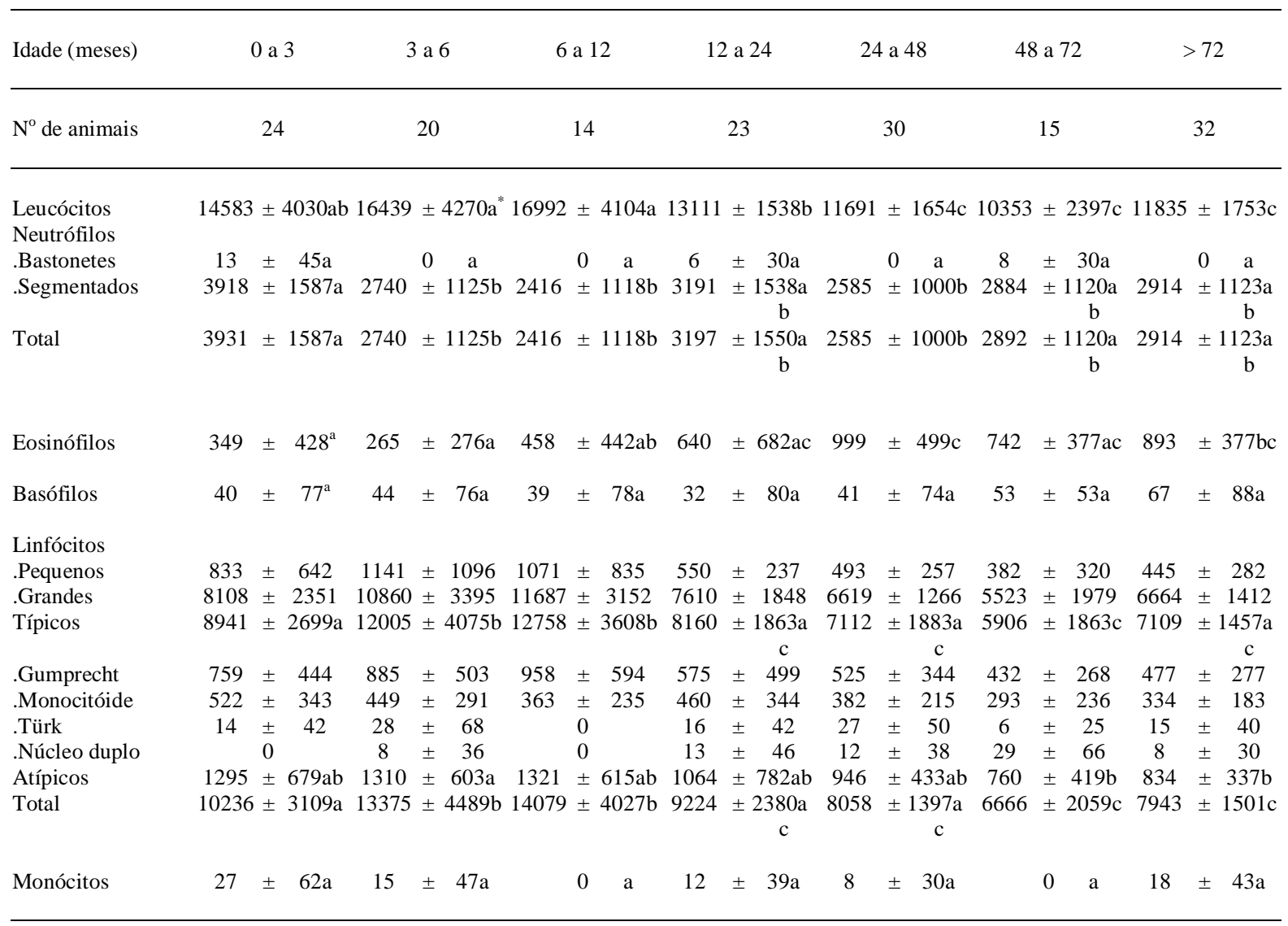


citos, não revelaram variações influenciadas pelos fatores etários.

\section{DISCUSSÃO}

A influência dos fatores etários sobre as variações dos componentes do leucograma de bovinos constatada neste estudo também foi observada por vários autores, tanto em bovinos de origem zebuína (MAGALHÃES， 1946; VALÊNCIA \& PERNA, 1980), quanto naqueles de origem taurina (GREATOREX, 1954, 1957 a e b; SOLIMAN \& ZAKI, 1965; LUMSDEN et al., 1980; GARCIA, 1989; BIRGEL JUNIOR, 1991).

O comportamento do número total de leucócitos, caracterizado por uma maior magnitude dos seus valores até a faixa etária de 6 a 12 meses de idade, quando atingiu o seu valor máximo, foi semelhante aos demonstrados por WITTWER \& BOHWALD (1974), MENESES et al. (1980), BERGLUND \& OLTNER (1983), GARCIA (1989) e BIRGEL JUNIOR (1991). Contudo, esses resultados diferiram dos registrados por WINGFIELD \& TUMBLESON (1973) e PEREIRA et al..(1987), os quais somente observaram os maiores valores do número total de leucócitos entre 4 e 10 anos de idade, bem como daqueles de pesquisadores que afirmaram que os fatores etários não exerceram influência sobre o número total de leucócitos (BRAUN, 1946; CONNER et al., 1967; KATUNGUKARWAKISHAYA et $\boldsymbol{a l} .$, 1985). Considerando-se os polimorfonucleares, o número absoluto total de neutrófilos, devido às variações das células com núcleo segmentado, apresentou decréscimo dos seus valores do nascimento até os 12 meses de idade, seguindo então com valores relativamente estáveis e independentes da influência dos fatores etários. Tal comportamento dos neutrófilos coincidiu com aqueles demonstrados por LORENZ et al. (1978) e JAIN (1986), sendo, todavia, discordante dos evidenciados por KATUNGUKA-RWAKISHAYA $\boldsymbol{e t}$ al. (1985) e BIRGEL JUNIOR (1991), cuja influência da idade sobre o número total de neutrófilos não pode ser caracterizada. O número absoluto de eosinófilos apresentou aumentos significativos dos seus valores a partir dos 24 meses de vida, fato também destacado por MAGALHÃES (1946) e VALÊNCIA \& PERNA (1980) em animais de origem zebuína, e por LORENZ et al. (1978) e BIRGEL JUNIOR (1991) em taurinos. As pequenas variações do número absoluto de basófilos mostraram que os fatores etários não exerceram influência significativa sobre essas células, sendo esses resultados similares aos da maioria dos autores pesquisados (BRAUN, 1946; SOLIMAN \& ZAKI, 1965; MENESES et al., 1980 e BIRGEL JUNIOR 1991).
Com relação às variações do número absoluto dos linfócitos típicos (pequenos e grandes) de fêmeas zebuínas sadias da raça Nelore, observou-se que sofreram a ação da evolução etária, tendo um aumento significativo durante o primeiro ano de vida e um valor médio máximo nos animais com idade variando entre 6 a 12 meses $\left(12758 \pm 3608 / \mathrm{mm}^{3}\right)$. A seguir, os linfócitos típicos apresentaram uma diminuição significativa do número absoluto, verificando-se o valor mínimo nos animais com idade entre 48 e 72 meses $\left(5906 \pm 1883 / \mathrm{mm}^{3}\right)$. A magnitude dos valores e o tipo de variação concordaram com aqueles apresentados por MAGALHÃES (1946) e VALÊNCIA \& PERNA (1980) em animais de origem zebuína, e por GREATOREX (1954) WITTWER \& BÖHWALD (1974), MENESES $\boldsymbol{e} t$ al.(1980), JAIN (1986) e BIRGEL JUNIOR (1991) em animais taurinos. Adicionalmente, pela semelhança de variação, pode-se afirmar que esse tipo celular foi o principal responsável pelo comportamento do número total de leucócitos. Considerandose os valores absolutos dos números dos linfócitos e neutrófilos totais durante o primeiro ano de vida dos zebuínos da raça Nelore, pode-se evidenciar que a influência dos fatores etários caracterizada, respectivamente, por aumento e diminuição desses tipos celulares, não está restrita aos 30 dias iniciais de vida, como observado por BIONDO (1996), mas sim, até os 12 meses de idade desses animais. A avaliação do número absoluto de monócitos observados nos animais desta pesquisa demonstrou a ausência da influência dos fatores etários, sendo o valor máximo registrado em animais incluídos na faixa etária de 0 a 3 meses $\left(27 \pm 62 / \mathrm{mm}^{3}\right)$. Esses achados concordaram com aqueles verificados por PENNY et al. (1966), LORENZ et al. (1978), MENESES $\boldsymbol{e t}$ al. (1980) e KATUNGUKARWAKISHAYA et al. (1985).

\section{CONCLUSÕES}

Os fatores etários exercem influência significativa sobre o leucograma de fêmeas zebuínas sadias da raça Nelore, pois os animais jovens apresentam números totais de leucócitos maiores do que nos adultos, sendo o quadro celular diferencial predominantemente linfocitário e suas variações atribuídas, em particular, ao comportamento do número absoluto de linfócitos típicos; em adição, o número absoluto total de linfócitos (típicos e atípicos) apresenta um aumento gradativo e significativo dos seus valores até um ano de vida. Os zebuínos da raça Nelore com até três meses de idade apresentam número significativamente maior de neutrófilos do que os animais mais velhos, sendo os neutrófilos 
com núcleo segmentado responsáveis por essa variação; em contra-posição, a elevação significativa dos eosinófilos é verificada a partir dos 24 meses de idade e os números absolutos de neutrófilos bastonetes, de basófilos e de monócitos não sofrem variações influenciadas pela evolução etária.

\section{REFERÊNCIAS BIBLIOGRÁFICAS}

ADAMS, R., GARRY, F.B., ALDRIDGE, B.M., et al. Hematologic values in newborn beef calves. American Journal Veterinary Research, v.53, p.944-950, 1992.

BAILEY, B.J.R. Tables of the Bonferroni " $t$ " statistic. Journal of the American Statistical Association, v.72, p.469-478, 1977.

BERGLUND, B., OLTNER, R. Blood levels of leukocytes, glucose, urea, creatinine, calcium, inorganic phophorus and magnesium in dairy heifers from three months of age to calving. Zentralblatt für Veterinärmedizin, Reihe A, v.30, p.59-71, 1983.

BIONDO, A.W. Hemograma de bovinos (Bos indicus) sadios da raça Nelore no primeiro mês de vida, criados no Estado de São Paulo: influência dos fatores etários e sexuais. Santa Maria-RS, 1996. 76p. Dissertação (Mestrado em Clínica Veterinária) - Curso de Pós-graduação em Medicina Veterinária, Universidade Federal de Santa Maria, 1996.

BIRGEL JUNIOR, E.H. O hemograma de bovinos (Bos taurus, Linnaeus, 1758) da raça Jersey, criados no Estado de São Paulo. Influências dos fatores etários, sexuais e da infecção pelo vírus da leucose bovina. São Paulo-SP, 1991. 172p. Dissertação (Mestrado em Patologia Bovina) - Curso de Patologia Experimental e Comparada, Universidade de São Paulo, 1991.

BIRGEL, E.H. Hematologia clínica veterinária. In: BIRGEL, E. H., BENESI, F.J. Patologia clínica veterinária. São Paulo , Sociedade Paulista de Medicina Veterinária, 1982. p.2-49.

BRAUN, W. Avarage levels of various constituents, physical properties, and formed elements of the blood of cows on pasture. American Journal Veterinary Research, v.7, p.450-454, 1946.

CONNER, G.H., LABELLE, J.A.J., WONNACOTT, B.S Effects of pregnancy and age on hemograms of HolsteinFriesian cattle in a herd with no evidence of leukemia. American Journal Veterinary Research, v.28, p.1303-1312, 1967.

GARCIA, M. Avaliação do leucograma de fêmeas bovinas da raç Holandesa branca e preta, naturalmente infectadas pelo Vírus da Leucose Bovina. São Paulo-SP, 1989. 67p. Dissertação (Mestrado em Patologia Bovina) - Curso de Patologia Experimental e Comparada, Universidade de São Paulo, 1989.

GREATOREX, J.C. Studies on the haematology of calves from birth to one year of age. British Veterinary Journal, v.110 p.1220-1238, 1954

GREATOREX, J.C. Observations on the haematology of calves and various breeds of adult dairy cattle. British Veterinary Journal, v.113, p.65-70, 1957a .
GREATOREX, J.C. Observations on the haematology of calves and various breeds of adult dairy cattle. British Veterinary Journal, v.113, p.469-481, 1957b

HOLMAN, H.H. Changes associated with age in the blood picture of the cow. British Veterinary Journal, v.112, p.91104, 1956.

JAIN, N.C. Schalm's veterinary hematology. 4 ed. Philadelphia : Lea \& Febiger, 1986. Cattle normal hematology with comments on response to disease: p.178-207.

KATUNGUKA-RWAKISHAYA, E., LARKIN, H., et al. Some haematological and blood biochemical components in conventionally reared calves. Irish Veterinary Journal, v.37, p.118-123, 1985 .

LORENZ, R.J., STRAUB, O.C., DONELLY, W.J.C., et al. Bovine haematology II. Comparative breed studies on the leukocyte parameters of several european cattle breeds as determined in national laboratories. Zentralblatt für Veterinärmedizin, Reihe B, v.25, p.245-256, 1978.

LUMSDEN, J.H., MULLEN, K., ROWE, R. Hematologic and biochemistry values, for female Holstein cattle. Canadian Journal Comparative Medicine, v.44, p.24-31, 1980.

MAGALHÃES, L.M. Contribuição ao estudo do sangue de bovinos. Belo Horizonte-MG, 1946. 126p. Tese (Professor Catedrático) - Escola Nacional de Veterinária, 1946.

MENESES, A.G., RODRIGUEZ, L.R., BOSCHINI, C. Comportamiento de las constantes sanguineas en Costa Rica: efecto de la raza y edade em vacas Holstein y Jersey. Ciencias Veterinárias, v.2, p.29-36, 1980.

PENNY, R.H.C., SCOFIELD, A.M., CEMBROWICZ, H Haematological values for the clinically normal bull. British Veterinary Journal, v.129, p.239-247, 1966.

PEREIRA, J.L., ORDEN, M.A., FERNANDEZ, M.J., et al. Variaciones hematológicas em relacion com la gestacion y la edade de la raza bovina autóctona Blanca Cacerena. Anales de Veterinaria de Murcia, v.3, p.93-97, 1987.

ROSAL, E.R., AVINA, A.G., TIROCO, V.G., et al. Parametros hematológicos normales en bovinos cebú (indubrasil) desde el nascimento hasta el destete, en clima subtropical A(f). Veterinária Mexico, v.13, p.13-18, 1982.

SOLIMAN , M.K., ZAKI, K. Blood picture of Friesian heifers from birth till maturity. Zentralblatt für Veterinärmedizin, Reihe A, v.13, p.467-473, 1965.

TENNANT, B., HARROLD, D., REINA-GUERRA, M., $\boldsymbol{e} \boldsymbol{t}$ al. Haematology of the neonatal calf: erytrocyte and leucocyte values of normal calves. Cornell Veterinarian, v.64, p.516532,1974

VALÊNCIA, G.R., PERNA, E.T. Valores hematológicos en los bovinos del Valle del Sinu. Revista do Instituto Colombiano Agropecuário, v.25, p.91-99, 1980.

WINGFIELD, W.E., TUMBLESON, M.E. Hematologic parameters, as a function of age, in female dairy cattle. Cornell Veterinarian, v.63, p.72-80, 1973.

WITTWER, F., BÖHWALD, H. Valores leucocitarios en hembras Overo Negro Europeo clinicamente sanas de diferentes edades de la zona de Valdívia. Archivos de Medicina Veterinaria, v.6, p.32-36, 1974 